\title{
Designing Competitions: How To Maintain Motivation For Losers
}

Rita J. Czaja, University of Wisconsin - Whitewater, USA

Richard G. Cummings, University of Wisconsin - Whitewater, USA

\begin{abstract}
Competition can either increase motivation by providing an added incentive or decrease motivation by threatening participants' sense of competence. The authors used two rounds of competition to examine whether competitions can be structured in ways that motivate high performance and do not discourage losers. Results indicated that a focus on learning and balanced ability levels mitigate any negative effect on losers' motivation.
\end{abstract}

Data availability: Data are available upon request.

Keywords: Intergroup competition, motivation

\section{INTRODUCTION}

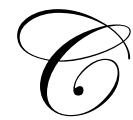

ompetition is common in the real world, but much has been written about the negative affects of competition in the classroom. Research shows that competition decreases intrinsic motivation. Few studies investigate the persistence of that effect. Understanding whether the decrease in motivation is temporary, or temporary under certain conditions, is important for educators deciding whether to use competition in their courses.

In addition, most of the pedagogical literature focuses on competition among individuals. Less has been written about intergroup competition, which can alleviate the negative aspects.

This paper describes the use of two rounds of intergroup competition in an online accounting course. Teams of students presented their solutions to cases (two teams per case). The other students and the instructor decided which presentation was better and provided feedback to the teams. Each team competed twice, against a different opponent. The change in scores between the first and second rounds shows that competitions can be structured in ways that motivate high performance and do not discourage effort. In addition, this study provides a "real world" test of results obtained from laboratory research.

\section{REVIEW OF THE LITERATURE}

Competition adds incentive and excitement to politics and athletic events; it is also common in business. In the same manner, competition can spark interest and increase students' desire to do well in academic activities (Tauer and Harackiewicz 2004; Kinzie, Hrabe and Larsen 1998; Good and Brophy 1990). There are national investment, marketing, and accounting competitions at the college level as well as spelling, geography, and problem-solving competitions for elementary and high school students. Competition clearly has the ability to increase motivation.

However, competition also has the potential to reduce motivation by threatening students' sense of competence and self-esteem. This is particularly true of zero-sum competition, where there is only one winner.

This section first reviews cognitive evaluation theory, a psychology-based theory that addresses competition and motivation. It then discusses attribution theory, which explains how some people can lose a 
competition without losing their sense of competence. These theories. along with social interdependence theory, suggest ways to structure competitive activities so that motivation is increased.

\section{Cognitive evaluation theory}

Motivation has been defined as a need for achievement, social approval, or power that drives people to take action (Covington 2000). Intrinsic motivation drives people to engage in activities that are experienced as inherently interesting and enjoyable. For example, pleasure and satisfaction may come from learning new things or accomplishing something. Cognitive evaluation theory describes the mechanism by which events, such as competitions, can cause changes in intrinsic motivation (Vallerand, Gauvin, and Haliwell 2001).

First, competition provides feedback about performance, which can affect perceived competence. Changes in perceived competence affect intrinsic motivation. Vallerand et al (2001) found that winners have a higher perception of competence than losers; and winners show more intrinsic motivation to continue an activity.

However, Vansteenkiste and Deci (2003) found that losers who receive positive feedback feel significantly more competent, and show significantly more intrinsic motivation, than losers who do not receive any feedback. Subjects in that study experienced positive feedback when they achieved a performance level that had been described in advance as very good. Vansteenkiste and Deci (2003) also found that intrinsic motivation does not differ significantly between losers who receive positive feedback and either winners or a no-competition/nofeedback control group. Accordingly, the assignment described in this study was graded based on specified criteria, so students can earn a high grade even if they lose the competition.

The second means by which events can affect intrinsic motivation is through a change in the perceived locus of causality or cause of one's behavior (Vallerand 2001). When people can decide whether or not to engage in an activity, their perceived locus of causality is internal, which can increase intrinsic motivation. When people experience pressure from their social environment to behave in a certain way, their perceived locus of causality is external. A lack of autonomy decreases intrinsic motivation. The assignment described in this study was graded and was a group project, so participation was expected by both the instructor and other group members. The lack of autonomy contributes to a decrease in intrinsic motivation.

Winners in a high-pressure setting show the same level of intrinsic motivation as subjects who receive no feedback about their performance (Vansteenkiste and Deci 2003). In other words, while positive feedback can increase intrinsic motivation, pressure can decrease intrinsic motivation. Pressure was set at a moderate level in this study. The instructions for the assignment encouraged students to do their best and try to win, but the assignment did not have a high impact on students' overall course grade. In addition, as noted earlier, a good grade on the assignment did not depend on winning the competition.

\section{Attribution theory}

Competition affects intrinsic motivation through the reasons people generate to explain wins and losses. The competition literature implicitly assumes that people attribute outcomes to their level of competence, but there are other possibilities. Attribution theory states that people explain an outcome in terms of its locus of controlwhether the cause is internal or external, stable or unstable, and controllable or uncontrollable. In general, people interpret events in ways that maintain self-esteem. For example, a good grade on a test will be attributed to ability or effort, but a poor grade will be attributed to a hard test or a bad day. Attributing successes to internal, stable, and controllable factors and failures to external, unstable, and uncontrollable factors is described as an optimistic explanatory style. To the extent that people adopt an optimistic explanatory style, losing a competition will not diminish their sense of competence and their intrinsic motivation will not be diminished.

Covington (2000) described "success-oriented" students as those who are interested in what they are studying and attracted by the challenge of achieving their goals. This description is consistent with students being intrinsically motivated. Success-oriented students tend to set goals that are reasonably attainable (Covington 1999). If failure occurs, the students interpret that event as a temporary setback that can be overcome with a little more 
effort. Thus, intrinsically motivated students appear likely to attribute failure to an unstable factor. Their sense of competence, and their intrinsic motivation, would not decrease.

The results found in the competition literature appear to be driven by people who attribute both good and bad events to stable, internal factors (e.g., competence). Covington's research suggests that these people do not have a high level of intrinsic motivation to engage in the task at hand. Subjects' intrinsic motivation could be low if the assigned task (e.g., solving a puzzle) does not appeal to them. Also, since the experimental task is often novel, subjects have no basis for setting "reasonable" goals. That could make competency-feedback more salient.

The attribution of losses to a lack of competence could also be a function of the timing of the measurement of intrinsic motivation. In laboratory studies, intrinsic motivation is typically measured by subjects' willingness to try again immediately after being told they had failed in their first attempt (e.g., Vallerand at al 2001, Tauer and Harackiwicz 2004, Vansteenkiste and Deci 2003). However, people can rebound from disappointments. People who are initially discouraged by their failure may adopt a different perspective later. Researchers have not examined the persistence of the lower level of intrinsic motivation. In some studies, subjects perform a task several times, but all repetitions are performed at one session without a break (Chaiken 1971; Reeve, Olson and Cole 1985; and Vansteenkiste and Deci 2003). Thus those studies do not allow for recoveries from the initial disappointment of a loss.

In this study, students competed twice, with at least a two-week interval between competitions. Multiple competitions provide an opportunity for students to improve their performance. People who use optimistic explanations for events, either immediately or after some time, will not experience a persistent decrease in their feelings of competence. Their motivation will be maintained, resulting in willingness to put effort into the second competition.

This perspective was encouraged in several ways. Competitions were between groups with randomly selected members. Relatively balanced ability levels are more likely when students are randomly assigned to groups than when students self-select into groups. When competitors are evenly matched, a close contest is more likely, which means students would be less likely to attribute failure to a lack of competence. In addition, students received specific feedback about their own and their competitor's performance. With balanced ability levels, losers from the first round can reasonably believe they are capable of doing the things that the winner did better. The loss would then be less likely to diminish effort in subsequent competitions.

The use of groups has another advantage in competitions. Individuals may feel a sense of responsibility to the group because the individual's work affects other people (see Johnson and Johnson 2005 for a review of this literature). This could counteract a fear of failure and reduce defensive behaviors like procrastinating.

Creating a sense of group identity might appear difficult in an online course, where students do not have the same opportunities for interaction as in a face-to-face class. However, social psychology experiments show that merely telling people that they belong to a group is sufficient for them to identify with the group (Vaughan, Tajfel and Williams 1981). Amichai-Hamburger (2005) demonstrated that this result, originally obtained in face-to-face settings, also occurs in the online environment.

\section{Social interdependence theory}

According to the social interdependence theory, the structure of participants' goals determines how they interact; the interaction in turn determines the outcome (Johnson and Johnson 2005). When goals encourage cooperation, individuals act in ways that increase the probability of achieving a joint goal. When goals encourage competition, individuals act in ways that decrease the probability of other participants' success.

Research shows that cooperation and competition result in similar performance when the following conditions are satisfied (Stanne, Johnson, and Johnson 1999; Johnson and Johnson 2005): 
1. There is not a heavy emphasis on winning.

2. Participants are evenly matched.

3. Rules are clear.

While cooperation and competition have been studied extensively, intergroup competition has received relatively little attention. The Stanne, Johnson, and Johnson (1999) meta-analysis therefore combines studies of intergroup competition with studies of cooperation (Tauer and Harackiewicz 2004). In a study designed to clarify the effect of intergroup competition, Tauer and Harackiewicz (2004) find that intergroup competition resulted in higher performance than pure cooperation, pure competition, and individual goals.

Other researchers have studied intergroup competition in marketing (Sparkman, Follows, and Zhou 1990) and in the core business courses (Umble, Umble, and Artz 2008). While increasing motivation was a major objective of Sparkman et al. (1990), the authors did not distinguish between intrinsic and extrinsic motivation and there was a strong emphasis on winning. Umble, Umble, and Artz (2008) measured perceived improvement in critical thinking and other skills. The study described in this paper is unique in examining the effectiveness of techniques to maintain intrinsic motivation in the losers of a competition.

The three conditions outlined by Stanne et al (1999) were operationalized as follows. A focus on learning (rather than winning) was created through the grade structure for the course and through the use of peer assessment. Grades for the assignment were based on assessment criteria; this means there did not have to be a large difference in the number of points received by the winners and the losers. Also, each assignment constituted a relatively small component of the course grade (about 4\%). This helps to moderate the pressure to achieve a high grade on the assignment.

Students also received grade points for peer assessment. For each case, two groups presented their solutions and the other students evaluated the presentations. This gave students practice in critical appraisal and reflective skills (multiple studies cited by Sivan 2000; Birenbaum 1996 and Sambell and McDowell 1998, cited by Prins et al 2005). Omelicheva (2005) found that peer assessment develops students' ability to apply assessment criteria to their own work. Thus, peer assessment may be the mechanism by which students are able to improve their own performance in the future.

Learning was given moderate emphasis in the instructor's directions for the peer assessment and in the feedback process. Students were told that their feedback to the groups presenting their work should show an understanding of the case and solution and help the groups improve their presentations. Students were also asked to compare the two presentations and discuss which group did a better job.

The second condition (evenly matched participants) was satisfied by using groups with randomly selected members (as discussed above). Clarity about rules (the third condition) was accomplished by providing the assessment criteria in advance along with detailed instructions regarding the assignment and expectations.

This study extends the literature on competition and motivation by examining whether losers exhibit a persistent decrease in intrinsic motivation. The structure of the competitive assignment also applies results obtained in laboratory experiments to a (virtual) classroom setting.

\section{RESEARCH METHODOLOGY}

The subjects were students in the online section of a beginning financial accounting course at a regional Midwestern university. The course is required for MBA students. Students were randomly assigned to groups of five to six students. The sample consists of eight groups in each of three semesters.

On a scheduled basis throughout the semester, two groups provided their solution to a case in the form of a presentation. The other students in the class individually viewed and evaluated the presentations. Assessment criteria were provided in advance by the instructor (see Table 1) and students marked the extent of their agreement with each criterion. The five-point scale ranged from Strongly Disagree to Strongly Agree. Response categories were 
assigned numeric scores with Strongly Disagree having a value of 1 . Students also provided narrative comments which were not used in this study. It is important to note that losers can experience positive feedback by earning high scores on the assessment criteria, even though the other group scored higher. Positive feedback is not limited to comments like "Good job" or "Well organized."

After the due date for the peer assessments, the presenters received a schedule of the points awarded by the instructor and the instructor's detailed comments. In addition, for their own and the other group, the presenters received a summary report of scores on the assessment criteria and all of their classmates' narrative comments.

Table 1

Assessment Criteria

1. The case problem and solution were easy to understand from the presentation.

2. The presenters did a good job connecting the topic and case to ideas we have learned in accounting.

3. The solution to the case seems reasonable and complete.

4. The presenters made the case "come alive" by providing a presentation that was pleasing to the eye and compelling to see.

5. I would be interested in viewing another case presentation from this team.

For each case, the average score was computed for each criterion. The average of the criterion scores was used as an assessment of the overall presentation. Sample means and standard deviations were then computed for each criterion and for the overall assessment. Each group presented two cases and t-tests were used to evaluate the change in score within and between the groups.

\section{RESULTS}

The average overall score was 4.18 for the first case and 4.18 for the second case on a five-point scale (see Table 2, Panel A). The change in overall score was zero and not significant ( $\mathrm{p}=.98)$. Removing three outliers increased the average change to 0.04 , which was also not significant $(\mathrm{p}=0.30)$.

Groups that lost in the first round of competition had an average overall score of 4.03 as compared to 4.33 for groups that won in the first round (see Table 2, Panel B). In the second round, the average overall score increased for first-round losers to 4.20 as compared to a decrease to 4.16 for first-round winners. The change in score is significantly different $(\mathrm{p}=0.05)$ between the two groups. This result is consistent with losers recovering from their first-round disappointment and learning to improve their performance.

For the first case, the average score for first-round losers was significantly below the average score for first-round winners on four of the five criteria. For the second case, scores for first-round losers are not significantly different from first-round winners on any criterion. Also, on four of the five criteria, scores for the first-round winners are not significantly different between the first- and second-rounds (see Table 2, Panel C). The results indicate that first-round losers improved to the level of first-round winners rather than first-round winners becoming overconfident and slacking off.

On the second case, grades determined by the instructor were not significantly different between first-round losers and first-round winners. This indicates that ability levels were balanced between the groups.

One concern about peer assessment is that students know less about the subject matter and assessment than instructors. Consequently, their assessments may not be valid measures of performance. In this study, the instructor and students agreed on which team performed better in 18 out of $24(75 \%)$ of the competitions. The correlation between the average peer assessment score and the instructor's point grade was $61 \%$. These results are consistent with prior research, which finds a high correlation between instructor and peer assessments (see literature reviews by Topping 1998 and Falchikov and Goldfinch 2000 in Sahin 2008). 
Table 2

Results

Amounts shown are group means (standard deviation).

\begin{tabular}{|c|c|c|c|c|c|c|}
\hline Question & $\begin{array}{c}1 \\
\text { (Ease of } \\
\text { under- } \\
\text { standing) }\end{array}$ & $\begin{array}{c}2 \\
\text { (Connected } \\
\text { to class) }\end{array}$ & $\begin{array}{c}3 \\
\text { (Reason-able } \\
\text { solution) }\end{array}$ & $\begin{array}{c}4 \\
\text { (Visual } \\
\text { appeal) }\end{array}$ & $\begin{array}{c}5 \\
\text { (Would like } \\
\text { to view } \\
\text { another) }\end{array}$ & Average \\
\hline \multicolumn{7}{|c|}{ Panel A - Full Sample } \\
\hline \multicolumn{7}{|c|}{ Full Sample } \\
\hline Case 1 means & $4.24(.22)$ & $4.38(.24)$ & $4.31(.31)$ & $3.90(.41)$ & $4.07(.29)$ & $4.18(.24)$ \\
\hline Case 2 means & $4.28(.31)$ & $4.34(.41)$ & $4.28(.37)$ & $3.93(.52)$ & $4.07(.37)$ & $4.18(.37)$ \\
\hline \multicolumn{7}{|c|}{ Panel B - Comparison between groups } \\
\hline \multicolumn{7}{|c|}{\begin{tabular}{l|l|} 
Case 1 & \\
\end{tabular}} \\
\hline First-round losers & $4.16(.18)$ & $4.26(.26)$ & $4.16(.34)$ & $3.70(.37)$ & $3.89(.21)$ & $4.03(.20)$ \\
\hline First-round winners & $4.33(.22)$ & $4.49(.16)$ & $4.46(.20)$ & $4.09(.35)$ & $4.25(.25)$ & $4.33(.19)$ \\
\hline Difference & -0.17 & $-0.24 *$ & $-0.30 *$ & $-0.39 *$ & $-0.36^{* *}$ & $-0.29 * *$ \\
\hline \multicolumn{7}{|l|}{ Case 2} \\
\hline First-round losers & $4.31(.31)$ & $4.33(.37)$ & $4.35(.26)$ & $3.97(.47)$ & $4.03(.37)$ & $4.20(.33)$ \\
\hline First-round winners & $4.26(.32)$ & $4.34(.46)$ & $4.21(.45)$ & $3.88(.59)$ & $4.10(.38)$ & $4.16(.42)$ \\
\hline Difference & 0.05 & -0.02 & 0.14 & 0.09 & -0.07 & 0.04 \\
\hline \multicolumn{7}{|c|}{ Panel C - Change from Case 1 to Case 2} \\
\hline First-round losers & $0.14(0.10)$ & $0.07(0.13)$ & $0.19(0.12)$ & $0.27(0.17)$ & $0.15(0.12)$ & $0.16(0.11)$ \\
\hline First-round winners & $-0.07(0.11)$ & $-0.14(0.14)$ & $-0.27(0.14)$ & $-0.21(0.20)$ & $-0.15(0.13)$ & $-0.17(0.13)$ \\
\hline
\end{tabular}

* Significant at the 0.05 level.

** Significant at the 0.01 level.

\section{DISCUSSION}

Students who are intrinsically motivated derive satisfaction and enjoyment from their studies. The assignment in this study included both factors that decrease intrinsic motivation and factors that increase it. Competition, the lack of autonomy inherent in a graded assignment, and moderate pressure decrease intrinsic motivation. Positive feedback based on performance standards and a moderate focus on learning increase intrinsic motivation. Balanced ability levels encourage students to attribute a first-round loss to unstable factors rather than a lack of competence (which would decrease their intrinsic motivation).

An interval between competitions gave first-round losers time to adopt a different perspective. While a loss may initially feel like a statement about competence, upon reflection, students may re-interpret the event as a learning experience with positive implications for future performance. The improvement in performance shown by first-round losers is consistent with no decrease in intrinsic motivation.

An alternative explanation is that the first-round loss resulted in ego-involved motivation rather than taskinvolved intrinsic motivation. First-round losers might have felt pressured to win on the second round in order to maintain their sense of competence. However, feedback obtained in student course evaluations does not support this explanation. Students answer three open-ended questions about strengths, weaknesses, and suggested improvements to the course in addition to 25 questions rating specific aspects of the course. At least $84 \%$ of the students responding answered one or more of the open-ended questions. On average, there were 84 comments per semester, of which 11 were about the assignment described in this study. One comment referred positively to the competition; there were no negative comments about the competitive nature of the assignment. Given the large number of total comments, it appears likely that students who felt strongly about the use of a competition would have said something. The course evaluation results indicate that students did not feel overly pressured by the competitive aspect of the assignment. 
At least some of the low scores on the first presentation could have been due to chance. All else equal, firstround losers would be expected to score higher, on average, in the second round. However, if a first-round loss has a persistent negative effect, the lower motivation would counter the statistical tendency of regression toward the mean. Either the negative effect on motivation is not persistent or there was a persistent negative effect and the steps taken to counter it were effective.

It is possible that students expected teams to learn from earlier presentations and thus raised their standards over time. Higher standards of performance for the second round would work against finding significant improvement.

Limitations of this study include a small sample size and the possible lack of generalizability inherent in quasi-experimental studies. Future research could include obtaining data from a control group that does not experience competition as well as laboratory research that examines the persistence of negative attributions regarding competence.

\section{AUTHOR INFORMATION}

Rita J. Czaja earned her Ph.D. from Northwestern University and is currently an assistant professor of accounting at University of Wisconsin-Whitewater. She teaches financial and managerial accounting at the undergraduate and MBA levels and has experience teaching an online course. Her research interests include program assessment, teaching strategies, and financial reporting.

Richard G. Cummings earned his Ph.D. from Kansas State University and is currently an associate professor of Accounting at the University of Wisconsin-Whitewater. He teaches individual taxation and MBA- Financial Accounting and has taught on-line courses for seven years. His research interests include empirical studies in horizontal equity in individual taxation, the effect of Subchapter S election in community banks, international accounting, and accounting education.

\section{REFERENCES}

1. Amichai-Hamburger, Y. 2005. Internet minimal group paradigm. CyberPsychology \& Behavior, 8 (2): 140-142.

2. Chaiken, A. L. 1971. The effects of four outcome schedules on persistence, liking for the task, and attributions of causality. Journal of Personality 39 (4): 512-526.

3. Covington, M. 1999. Caring about learning: the nature and nurturing of subject-matter appreciation. Educational Psychologist, 34 (2): 127:136.

4. Covington, M. V. 2000. Goal theory, motivation, and school achievement: an integrative review. Annual Review Psychology 51: 171-200.

5. Good, T. L., and Brophy, J.E. 1990. Educational Psychology: A Realistic Approach (fourth edition). New York: Longman.

6. Johnson, D. W. and Johnson, R.T. 2005. New developments in social interdependence theory. Genetic, Social and General Psychology Monographs 131 (4): 285-358.

7. Kinzie, M. B., Harbe, M. E., and Larsen, V. A. 1998. An instructional design case event: exploring issues in professional practice. Educational Technology Research and Development 46 (1): 53-71.

8. Omelicheva, M. Y. 2005. Self and peer evaluation in undergraduate education: structuring conditions that maximize its promises and minimize the perils. Journal of Political Science Education, 1:191-205.

9. Prins, F. J., Sluijsmans, D. M. A., Kirshner, P. A. and Strijbos, J. 2005. Formative peer assessment in a CSCL environment: a case study. Assessment \& Evaluation in Higher Education. 30 (4): 417-444.

10. Reeve, J., Olson, B. C., Cole, S. G. 1985. Motivation and performance; two consequences of winning and losing in competition. Motivation and Emotion, 9 (3): 291-298.

11. Sahin, S. 2008. An application of peer assessment in higher education. The Turkish Journal of Educational Technology 7 (April): 5-10.

12. Sivan, A. 2000. The implementation of peer assessment: an action research approach. Assessment in Education: Principles, Policy \& Practice 7 (2): 193-213. 
13. Sparkman, Follows, and Zhou. 1990. The use of inter-sectional competition with an oral project in the introductory marketing course. Journal of Marketing Education 12 (3): 34-41.

14. Stanne, M. B., Johnson, D. W., and Johnson, R. T. 1999. Does competition enhance or inhibit motor performance: a meta-analysis. Psychology Bulletin 125 (1): 133-154.

15. Tauer, J. and Harackiewicz, J. 2004. The effects of cooperation and competition on intrinsic motivation and performance. Journal of Personality and Social Psychology 86 (6): 849-861.

16. Umble, E., Umble, M., and Artz, K. 2008. Enhancing undergraduates' capabilities through team-based competitions: the Edward Jones challenge. Decision Sciences Journal of Innovative Education 6 (1): 1-27.

17. Vallerand, R. J., Gauvin, L. I., and Halliwell, W. 2001. Effects of zero-sum competition on children's intrinsic motivation and perceived competence. The Journal of Social Psychology 126 (4), 465-472.

18. Vansteenkiste, M. and Deci, E. 2003. Competitively contingent rewards and intrinsic motivation: can losers remain motivated? Motivation and Emotion 27 (4): 273-299.

19. Vaughan, G. M, Tajfel, H., and Williams, J. 1981. Bias in reward allocation in an intergroup and an interpersonal context. Social Psychology Quarterly 44(1): 37-42. 